\title{
Stroke in Coronary Bypass Surgery
}

\author{
W.R. WAYNE MARTIN and STANLEY A. HASHIMOTO
}

\begin{abstract}
A$ retrospective review of 253 patients who underwent coronary bypass surgery was performed. Eight (3.2\%) had suffered a stroke either intra-operatively (4) or during the early post-operative period (4). A comparison of pre-operative and intra-operative variables between the stroke group and the stroke-free group showed a significant difference only for the hemoglobin level $(p<0.01)$. All intraoperative strokes occurred in patients who had undergone femoral cannulation; it is suggested that this may have been a source of embolic material in these patients. An embolic origin for most of the strokes (both intra-operative and post-operative) is postulated on the basis of clinical and pathological findings.
\end{abstract}

RESUME: Nous présentons une revue rétrospective de 253 patients ayant subi un pontage coronaire. Huit patients (3.2\%) ont subi une thrombose cérébrale soit pendant l'opération (4), soit tôt après l'opération (4). Une comparaison des multiples variables ne montre qu'une différence dans le taux d'hémoglobine entre les groupes devant subir une thrombose, et les autres. Toutes les thromboses per-opératoires se sont produites chez des patients ayant eu une cannulation fémorale, peut-être la source du matériel embolique chez ces patients. La clinique et la pathologie favorisent une origine embolique pour la plupart de ces thromboses per et post-opératoires.

Division of Neurology, The University of British Columbia and The Vancouver General Hospital, Vancouver, British Columbia.

Reprint Requests to: Dr. W.R.W. Martin, Division of Radiation Sciences, Washington University Schoo of Medicine, 510 South Kingshighway, St. Louis, Missouri 63110 , U.S.A.

\section{INTRODUCTION}

Neurological disorders are wellrecognized complications of open-heart surgery. The reported incidence varies according to study format and to the criteria used for the definition of neurological disturbance. Gilman (1965) found post-operative cerebral disturbances in $34 \%$ of 35 patients. In a review of 417 patients, Branthwaite (1972) noted a $19.2 \%$ incidence of neurological dysfunction; Tufo, et al. (1970) studied 100 patients prospectively and noted the occurrence of abnormal neurological signs in $44 \%$ of patients who survived beyond the fifteenth post-operative day. These disorders were secondary to cerebral ischemia and tended to be related to age, to arterial hypotension during cardiopulmonary bypass, and to duration of bypass.

These studies dealt primarily with valve replacement or repair of congenital defects. In recent years the emphasis in cardiac surgery has shifted to the saphenous vein bypass graft as a treatment for severe atherosclerotic heart disease. Reviews of postoperative bypass graft complications suggest a much lower incidence of neurological disorders. Assad-Morell, et al. (1975) followed 500 patients for 18-42 months after surgery and found only one "cerebro-vascular accident" which occurred as a late complication. Sheldon and Grinfeld (1971) discuss the post-operative assessment of 300 patients but make no mention of neurological dysfunction. Two recent reviews have found the incidence of ischemic cerebral infarction to be $0.7 \%$ (Lee, et al., 1979) and 0.8\% (GonzalezScarano and Hurtig, 1981).

Others have provided anecdotal evidence suggesting that cerebral ischemia does occur both as an intraoperative and post-operative complication of coronary bypass surgery (Russell and Bharucha, 1978; Bounds, et al., 1976), but its true incidence is difficult to ascertain. Therefore, a retrospective review of coronary bypass surgery was performed in an attempt to determine the incidence of intra-operative and post-operative stroke, and the presence of any factors which may contribute to this incidence.

\section{METHODS}

The charts of all patients who underwent coronary artery bypass surgery between January 1 and December 31,1978 at the $V$ ancouver General Hospital were reviewed. This comprised a total of 280 patients. Of these patients, 26 were excluded because concomitant valve replacement or closure of congenital ventricular septal defect was performed. One additional patient was rejected because of uncertainty regarding the significance of neurological findings. The remaining 253 patients are considered in this review. The surgical bypass was of a single vessel in $12.2 \%$, two vessels in $31.2 \%$, three vessels in $38.8 \%$, four vessels in $15.8 \%$, and five vessels in $2.0 \%$. A concomitant ventricular aneurysmectomy was performed in 17 patients.

A stroke was defined clinically as a focal neurological deficit of relatively sudden onset and lasting longer than 24 hours. The pathological finding of focal or multifocal changes suggestive of cerebral ischemia was also felt to represent a stroke whether or not the above clinical syndrome had been observed.

Each chart was reviewed with regard to possible contributory historical, preoperative, and intra-operative factors. These factors are listed in Tables 2 and 3. A statistical comparison was made between the stroke and the non-stroke groups for each of these factors, using either Student's t-test or the chi-square test.

\section{RESULTS}

There were 253 procedures performed in 252 patients. Eight patients (3.2\%) were identified in whom an acute cerebrovascular event had occurred either intra-operatively or post- 
TABLE 1

Clinical Data from Patients with Intra-operative / Post-operative Strokes

\begin{tabular}{|c|c|c|c|}
\hline Patient \# Age Operation & Stroke Onset & Anatomical Localisation & Clinical Features \\
\hline 67 4-vessel bypass & intra-operative & $\begin{array}{l}\text { multiple hemorrhagic infarcts in } \\
\text { MCA distribution bilaterally } \\
\text { (pathology) }\end{array}$ & $\begin{array}{l}\text { Did not regain consciousness P.O.; developed } \\
\text { hemopericardium and cardiac arrest at } 6 \text { hours P.O. } \\
\text { Hemopericardium drained. Three days later noted } \\
\text { to remain comatose with decerebrate posturing. } \\
\text { Death on 4th P.O. day. }\end{array}$ \\
\hline
\end{tabular}

$\begin{array}{rr}269 \begin{array}{l}1 \text {-vessel bypass } \\ \text { aneurysmectomy }\end{array} & \begin{array}{r}\text { intra-operative } \\ \text { infarction in posterior } 2 / 3 \text { of } \\ \end{array} \\ & \text { R MCA territory with sparing of } \\ & \text { basal ganglia (pathology) }\end{array}$

$3 \quad 47$ 3-vessel bypass intra-operative lateral medullary infarction

4523 -vessel bypass intra-operative infarction in R MCA territory

Dense $\mathrm{L}$ hemiplegia noted immediately P.O.

Developed cardiac and septic shock, and renal

failure on 6th P.O. day. Death on 10th P.O. day. (clinical \& CT scan)

Classical Wallenberg syndrome noted immediately P.O.

Left hemiparesis, conjugate eye deviation to the right and a left homonymous hemianopsia noted immediately P.O.

545 4-vessel bypass P.O. Day 2 multiple bilateral infarcts

Previous mild $\mathrm{L}$ hemiparesis with recovery. (clinical)

P.O. day 2, recurrence of $L$ sided weakness; pseudobulbar affect, spastic tetraparesis and bilateral cerebellar signs on examination.

\begin{tabular}{|c|c|c|c|c|}
\hline 6 & 45 3-vessel bypass & P.O. Day 4 & $\begin{array}{l}\text { infarction in } \mathrm{R} \text { optic radiation } \\
\text { (clinical) }\end{array}$ & $\begin{array}{l}\text { Sudden awareness of decreased vision to the left; } \\
\mathrm{L} \text { inferior quadrantic defect on examination. }\end{array}$ \\
\hline 7 & $\begin{array}{l}65 \text { 4-vessel bypass } \\
\text { aneurysmectomy }\end{array}$ & P.O. Day 10 & $\begin{array}{l}\text { infarction in Broca's area of } \\
\text { L frontal lobe (clinical) }\end{array}$ & $\begin{array}{l}\text { Well until P.O. day } 10 \text {, then sudden onset } \\
\text { non-fluent dysphasia with intact comprehension. }\end{array}$ \\
\hline 8 & 37 2-vessel bypass & P.O. Day 11 & $\begin{array}{l}\text { infarction in L parieto- } \\
\text { occipital region (clinical) }\end{array}$ & $\begin{array}{l}\text { Well until P.O. day } 11 \text {, then complained of } \\
\text { visual difficulty; examination showed alexia, } \\
\text { agraphia, } \mathrm{R} \text { hemiparesis (mild) and cortical } \\
\text { sensory loss (severe) and } \mathrm{R} \text { homonymous hemianopia }\end{array}$ \\
\hline
\end{tabular}

P.O. = post-operative

$\mathrm{MCA}=$ middle cerebral artery

$\mathrm{R}=$ right

$\mathrm{L}=$ left

operatively before discharge from hospital. The mean duration of postoperative hospitalization amongst stroke-free survivors was 11.5 days (range 7 - 63). The relevant clinical data from these patients is summarized in Table 1.

The pre-operative variables for the stroke group vs the non-stroke group are listed in Table 2 with either the mean value for the group, or with the number and percentage of patients in the group who had the listed characteristic. The only pre-operative factor which is significantly different between groups is the blood hemoglobin level of $13.3 \pm 1.7 \mathrm{gm} / \mathrm{dl}$ in the stroke group vs $14.7 \pm 1.2 \mathrm{gm} / \mathrm{dl}$ in the non-stroke group ( $p<0.01$, Student's t-test).
The operative variables for the stroke group vs the non-stroke group are listed in a similar fashion in Table 3. The only variable which is significantly different between groups is the cannulation route, i.e. the route by which oxygenated blood is returned to the patient from the cardio-pulmonary pump. In the stroke group all patients underwent femoral cannulation as compared to $48 \%$ in the non-stroke group ( $p<0.02$, chi-square test). This difference is no longer statistically significant, however, if the intraoperative and post-operative strokes are considered separately. Duration of bypass and minimum perfusion pressure was virtually identical in both groups. Neither the number of bypassed vessels, nor the performance of concomitant ventricular aneurysmectomy appeared to be related to the occurrence of stroke.

\section{DISCUSSION}

Any conclusion drawn in a retrospective review of this nature is dependent on the reliability of the recorded data. The diagnosis of stroke was made during hospital admission by a neurologist in all but one case, and the clinical information available in all cases was sufficient for accurate diagnosis at the time of review. The quantitative variables represented by parametric statistics in Table 2 and all data in Table 3 are drawn from information recorded in all patients and are felt to be accurate. Similarly, definite information regarding the presence or 
TABLE 2

Pre-operative Variables

Age (years) mean \pm SD

female

Weight $(\mathrm{kg})$ mean $\pm \mathrm{SD}$

Cerebrovascular disease ${ }^{1}$

Peripheral vascular disease ${ }^{1}$

Myocardial infarction ${ }^{2}$

Diabetes mellitis ${ }^{3}$

Smokers ${ }^{4}$

Family history ${ }^{5}$

Arrhythmias ${ }^{6}$

Blood pressure ${ }^{7}$

$$
\text { systolic }(\mathrm{mm} \mathrm{Hg}) \text { mean } \pm \mathrm{SD}
$$$$
\text { diastolic }(\mathrm{mm} \mathrm{Hg}) \text { mean } \pm \mathrm{SD}
$$

Serum Cholesterol $(\mathrm{mg} / \mathrm{dl})$ mean $\pm \mathrm{SD}$

Serum Triglycerides $(\mathrm{mg} / \mathrm{dl})$ mean $\pm \mathrm{SD}$

Hemoglobin $(\mathrm{g} / \mathrm{d} l)$ mean $\pm \mathrm{SD}$

Stroke
$(\mathbf{N}=8)$

$55 \pm 12$

$3(38 \%)$

$5(62 \%)$

$75 \pm 11$

$1(13 \%)$

$1(13 \%)$

$7(88 \%)$

Non-stroke

$(\mathrm{N}=\mathbf{2 4 5})$

$$
54 \pm 8
$$$$
39(16 \%)
$$

$206(84 \%)$

$75 \pm 12$

$13(5 \%)$

$17(7 \%)$

$140(57 \%)$

$12(5 \%)$

$3(38 \%)$

$5(63 \%)$

$135(55 \%)$

$1(13 \%)$

98(40\%)

$20(8 \%)$

$123 \pm 21$

$123 \pm 21$

$74 \pm 12$

$76 \pm 12$

$259 \pm 70$

$254 \pm 57$

$231 \pm 108$

$236 \pm 126$

$13.3 \pm 1.7$
Significance

NS

NS

NS

NS

NS

NS

NS

NS

NS

NS

NS

NS

NS

NS

$\mathrm{p}<0.01$

levidence from history, or from admission physical examination

${ }^{2}$ evidence from history, or from pre-operative ECG

${ }^{3}$ evidence from history, or from blood glucose levels

"evidence from history

'history of relatives < 65 years of age with $\mathrm{MI}$, stroke, or peripheral vascular disease

${ }^{6}$ On pre-operative ECG (atrial fibrillation, PVC's, $2^{0}-3^{\circ} \mathrm{A}-\mathrm{V}$ block, sick sinus), or by history

'recorded at time of pre-operative anesthetic assessment

TABLE 3

\section{Operative Variables}

$\begin{array}{lccc} & \begin{array}{c}\text { Stroke } \\ (\mathbf{N = 8})\end{array} & \begin{array}{c}\text { Non-stroke } \\ (\mathbf{N}=\mathbf{2 4 5})\end{array} & \text { Significance } \\ \text { Pump time (min) mean } \pm \text { SD } & 108 \pm 27 & 102 \pm 38 & \text { NS } \\ \text { Cross-clamp time (min) mean } \pm \text { SD } & 68 \pm 18 & 66 \pm 26 & \text { NS } \\ \text { Perfusion pressure (mm Hg) mean } \pm \text { SD } & 47 \pm 8 & 48 \pm 8 & \text { NS } \\ \text { Cannulation' - femoral } & 8(100 \%) & 118(48 \%) & \text { p<0.02* } \\ \text { aortic } & 0 & 127(52 \%) & \\ \text { Oxygenator - bubble } & 8(100 \%) & 223(91 \%) & \text { NS } \\ \text { membrane } & 0 & 22(9 \%) & \\ \text { Temperature }^{2} \text { - normothermic } & 8(100 \%) & 196(80 \%) & \text { NS } \\ \quad \text { hypothermic } & 0 & 49(20 \%) & \end{array}$

'arterial access via femoral artery or ascending aorta

${ }^{2}$ core temperature during cardiopulmonary bypass (hypothermia $<30^{\circ} \mathrm{C}$ )

see text absence of the historical factors listed in Table 2 was available in most cases. Any errors in these figures are likely to be in the form of false negatives rather than false positives, and are likely to affect both stroke and non-stroke groups.

In this series the overall incidence of stroke was $3.2 \%$. It seemed likely that one additional patient had a postoperative stroke, but since the information available was insufficient for diagnostic certainty this patient was excluded. Other unrecognized cases may exist. This is far less than the incidence of neurological abnormalities of $19.2 \%$ - $44 \%$ reported following open heart surgery for valve replacement and repair of congenital defects (Gilman, 1965; Branthwaite, 1972; Tufo, et al., 1970 ), but is somewhat greater than the incidence of ischemic cerebral infarction of $0.7 \%$ following coronary artery bypass reported by Lee, et al. (1979), and of $0.8 \%$ reported by GonzalezScarano and Hurtig (1981).

Cerebral embolism has frequently been suggested to be of etiologic importance and numerous potential embolic sources have been identified. Manipulation of the heart and atherosclerotic vessels may dislodge embolic material as may manipulation of heavily calcified cardiac valves; cross-clamping of the ascending aorta may crush atherosclerotic plaques which may then embolise. Microembolisation to cerebral vessels may occur from platelet aggregates formed in the pump oxygenator (Ashmore, et al., 1968), from lipid globules produced at the gasblood interface in the pump oxygenator (Kessler and Patterson, 1970), or from air emboli generated within the oxygenator. Fat emboli may also result from median sternotomy (Gilman, 1965; Hodge, et al., 1976), and air emboli from air trapped in the heart during surgery and subsequently expelled as left ventricular contraction resumes.

Changes in anesthetic and operative technique have minimized some of these factors. The use of small pore filters in the arterial line from the pump has decreased the dissemination of microemboli arising within the pump oxygenator (Connell, et al., 1973). The membrane oxygenator has been associated with greatly decreased microembolus counts even in the absence of 
an arterial filter when compared with the bubble oxygenator (Carlson, et al., 1973). Some of the above embolic sources are clearly less important in coronary bypass surgery than in open heart surgery. Manipulation of heavily calcified valves is an uncommon problem in the former. A small cardiotomy is performed during coronary bypass, for the placement of either a left atrial or left ventricular vent, and the possibility of air-trapping within the left ventricle is much less than in open heart surgery where a more extensive cardiotomy is performed.

Decreased cerebral perfusion during bypass has been implicated by some authors. This may result in border zone cerebral infarction (Gilman, 1965; Russell and Bharucha, 1978), often bilateral, or in ischemic neuronal damage in sensitive areas. Cerebral blood flow and metabolism is often depressed during the initiation of cardiopulmonary bypass (Branthwaite, $1973 \&$ 1974). The degree of intraoperative depression of cerebral activity as reflected in the electroencephalogram may be related to the severity of neurological sequelae as well as to the minimum perfusion pressure during bypass (Stockard, et al., 1973). These authors used a hypotension index to express the degree and duration of mean arterial blood pressure drop below $50 \mathrm{~mm} \mathrm{Hg}$. Patients in whom the index was 100 or greater had an $86 \%$ incidence of cerebral deficit compared to a $19 \%$ incidence in those with an index of less than 100. These patients had developed signs of diffuse cerebral dysfunction and the two cases studied neuropathologically showed diffuse anoxic changes. Tufo, et al. (1970) found that the presence of cerebral damage correlated with the lowest level of mean arterial pressure and with the duration this level was maintained. In patients with a minimum mean blood pressure of 60 $\mathrm{mm} \mathrm{Hg}$ or greater, there was a $27 \%$ incidence of cerebral damage as compared to a $78 \%$ incidence in those with a mean blood pressure of $40 \mathrm{~mm} \mathrm{Hg}$ or less. The most common neuropathologic finding in those who died was that of diffuse cerebral anoxia. Russell and Bharucha (1978) report the pathologic findings of cerebral infarc- tion bilaterally in the border zones between areas of arterial supply (especially between middle cerebral artery and posterior cerebral artery), supporting the occurrence of intraoperative hypotension as an etiologic factor.

It has been suggested that some patients, especially the elderly, have an increased tendency to develop neurological dysfunction from mild hypotensive episodes because of pre-existing atherosclerotic cerebrovascular disease (Gilman, 1965; Stockard, et al., 1973; Russel and Bharucha, 1978). There is evidence, however, that such dysfunction is unlikely to be focal. Kendell and Marshall (1963) showed that hypotension will cause symptoms of general cerebral ischemia before focal neurological signs develop, even in patients with carotid territory transient ischemic attacks. In a neuropathologic study of brains from 135 patients who died soon after successful resuscitation after cardiac arrest, all but two had histologic changes of cerebral anoxia, while only $5.2 \%$ had recent cerebral infarcts which had originated at the time of cardiac arrest (Torvik and Skullerud, 1976). These recent infarcts were not related to the degree of cerebral atherosclerosis, whereas the old infarcts seen in the same material were closely related to the degree of cerebral atherosclerosis. These studies suggest that intra-operative hypo-perfusion is not likely to result in focal cerebral damage in these patients.

In our patients, age, duration of cardiopulmonary bypass, and minimal arterial pressure during bypass were not significant factors, nor was the presence of pre-existent cerebrovascular disease (as evident from the recorded past history and the neurological and vascular examination). Concomitant ventricular aneurysmectomy did not significantly affect stroke incidence. No conclusions could be drawn regarding the use of the membrane oxygenator vs the bubble oxygenator because the former was used in fewer than $9 \%$ of the total patients. Similarly, no conclusions could be drawn regarding any possible protective effect of intra-operative hypothermia.
There was a significant difference in the pre-operative hemoglobin level. This difference is small, but is significant at the $\mathrm{p}<0.01$ level (Student's ttest). A decreased hemoglobin level results in decreased oxygen transport and makes the brain more sensitive to any further anoxia or ischemia.

The pump oxygenator receives venous blood via cannulation of the inferior and superior vena cava. Oxygenated blood is returned to the systemic arterial circulation via the ascending aorta or the femoral artery. In the case of femoral cannulation there is retrograde flow in the descending aorta such that arterial blood is delivered from the femoral artery to the aortic arch. The aortic bifurcation and the femoral artery often have a more severe degree of atherosclerosis than the ascending aorta, and femoral cannulation may therefore dislodge fragments of atherosclerotic material more readily than aortic cannulation. These fragments may embolise up the aorta and into the carotid or vertebral arteries. This hypothesis is supported by the observation that all four patients with intra-operative strokes had undergone femoral cannulation as compared to $48 \%$ of non-stroke patients, although this difference does not reach statistical significance (i.e., $p>0.05$ ). A case report of cholesterol emboli to cerebral arteries occurring with retrograde aortic perfusion has been previously published by Price and Harris (1970).

Embolisation is the probable etiology of stroke in most of our patients. Patient \#1 had pathological evidence of multiple areas of hemorrhagic infarction in the middle cerebral artery distribution bilaterally. The proximal and distal internal carotid artery and the proximal middle cerebral artery was patent bilaterally. There was post-mortem evidence of very recent myocardial infarction, but neither mural thrombus formation nor other cardiac source of embolus was evident. This patient did suffer a significant post-operative hypotensive episode, but the cerebral pathology is more likely to be secondary to multiple emboli than to generalised cerebral hypo-perfusion. Patient \#2 had pathological evidence of hemorrhagic infarction in the posterior 
two-thirds of the right middle cerebral artery territory sparing the basal ganglia suggesting occlusion of multiple middle cerebral artery branches, likely embolic. Evidence for recent myocardial infarction was present, but there was no mural thrombus formation, no thrombus formation at the ventricular aneurysmectomy site, nor any other evident cardiac source of embolus. Both these patients had suffered intra-operative strokes and had neuropathologic findings strongly suggestive of multiple emboli although there was no evident source of embolism at autopsy. We suspect that femoral cannulation was the embolic source.

Two other patients suffered intraoperative strokes. Patient $\# 3$ had a lateral medullary infarction which may be secondary to either embolic or thrombotic occlusion of the posterior inferior cerebellar artery or of the ipsilateral vertebral artery. Patient \#4 suffered infarction in the right middle cerebral artery distribution suggesting either embolic or thrombotic occlusion of the proximal middle cerebral artery or of the internal carotid artery.

The initial manifestations of stroke were observed post-operatively after a period of apparent normal recovery ranging from one day to ten days in four patients. Patient \#5 had acute bilateral lesions superimposed upon an old unilateral lesion, likely on an embolic basis. The remaining patients all appeared to have unifocal lesions. The blood supply to the optic radiation is largely from the terminal branches of the middle cerebral artery, especially the superior temporo-occipital sylvian artery (Glaser, 1978). This branch was likely occluded in Patient \#6. Middle cerebral branch occlusion also occurred in Patient \#7, and posterior cerebral occlusion in Patient \#8. According to Fisher (1975), embolism accounts for $90 \%$ of cases of middle cerebral stem or branch occlusion, and for $75 \%$ of cases of posterior cerebral artery occlusion. None of these infarcts were border zone lesions suggestive of general cerebral hypo-perfusion.

The occurrence of stroke in the postoperative period has been noted previously (Stoney, et al., 1971). Bounds, et al. (1976) describe a patient who developed a left inferior quadrant- anopia on the 8th post-operative day and a progressive left hemiparesis on the 13th post-operative day. This patient at post-mortem had thrombus adherent to the aortic sutures extending into the aortic lumen, and a large nonadherent thrombus of probable embolic origin in the proximal right middle cerebral artery. They also suggest that graft thrombosis with retrograde propagation to the aorta-graft anastamosis may give rise to embolus formation. These delayed complications are unlikely to be related to femoral cannulation since retrograde aortic flow is no longer present once cardiopulmonary bypass has ceased. The post-operative strokes in this study appeared clinically to be of embolic origin, but the source of emboli was not identified.

The management of patients with coexistant cerebrovascular and coronary artery disease is controversial. Mehigan, et al. (1977) suggest that coronary artery bypass candidates should be screened for the presence of extracranial cerebrovascular disease, and that patients with significant lesions should undergo surgical reconstruction either before or simultaneously with coronary artery bypass, regardless of the presence or absence of neurological symptoms. However, Turnipseed, et al. (1980) showed that post-operative cerebrovascular complications were of similar incidence in patients with severe carotid stenosis or occlusion and patients with relatively normal carotid arteries, established by pre-operative non-invasive screening. Similarly, Barnes, et al. (1980) showed that although severe asymptomatic carotid occlusive disease is not uncommon, that perioperative stroke is rare in affected patients. Our data is insufficient to accurately report the incidence of carotid artery disease because no screening method beyond the clinical exam was used. However, there was no significant difference between the stroke and the non-stroke groups in the incidence of the clinical diagnosis of cerebrovascular disease. This, as well as the data from the latter two studies, suggests that routine prophylactic carotid artery surgery in coronary bypass candidates with asymptomatic carotid artery disease is not indicated.
The incidence of intra-operative and early post-operative stroke although small is not trivial and should be included in any discussion of risks and benefits from coronary bypass surgery. An embolic source for many of these strokes is postulated, and in the case of intra-operative strokes may be related to the route of cannulation. Prospective studies are indicated to attempt to elucidate the source and solution of this problem.

\section{ACKNOWLEDGEMENTS}

Special thanks to Dr. A.A. Eisen, Dr. R. Harrop and to the members of the Division of Cardiothoracic Surgery at the Vancouver General Hospital.

\section{REFERENCES}

AGUILAR, M.J., GERBODE, F., HILL, J.D. (1971). Neuropathologic complications of cardiac surgery. J Thorac Cardiovasc Surg 61, 676-685.

ASHMORE, P.G., SVITEK, V., AMBROSE, P. (1968). The incidence and effects of particulate aggregation and microembolism in pump oxygenator systems. J Thorac Cardiovasc Surg 55, 691-697.

ASSAD-MORELL, J.L., FRYE, R.L. CONNOLLY, D.C., et al. (1975). Aortacoronary artery saphenous vein bypass surgery: clinical and angiographic results. Mayo Clin Proc 50, 379-386.

BARNES, R.W., MARSZALEK, P.B., RITTGERS, S.E. (1980). Asymptomatic carotid disease in preoperative patients. Stroke 11, 136.

BOUNDS, J.V., SANDOK, B.A., BARNHORST, D.A. (1976). Fatal cerebral embolism following aorto-coronary bypass graft surgery. Stroke 7, 611-614.

BRANTHWAITE, M.A. (1972). Neurological damage related to open-heart surgery. Thorax 27, 748.753.

BRANTHWAITE, M.A. (1973). Detection of neurological damage during open-heart surgery. Thorax 28, 464-472.

BRANTHWAITE, M.A. (1974). Cerebral blood flow and metabolism during openheart surgery. Thorax 29, 633-638.

CARLSON, R.G., LANDE, A.J., LANDIS, B., et al. (1973). The Lande-Edwards membrane oxygenator during heart surgery: oxygen transfer, microemboli counts, and BenderGestalt visual motor test scores. J Thorac Cardiovasc Surg 66, 894-905.

CONNELL, R.S., PAGE, U.S., BARTLEY, T.D., BIGELOW, J.C., WEBB, M.C. (1973). The effect on pulmonary ultrastructure of dacron-wool filtration during cardiopulmonary bypass. Ann Thorac Surg 15, 217-229. 
FISHER, C.M. (1975). The anatomy and pathology of the cerebral vasculature. In: Meyer, J.S., ed. Modern concepts of cerebrovascular disease. New York, N.Y., Spectrum Publications, 1-41.

GILMAN, S. (1965). Cerebral disorders after open-heart operations. N Engl J Med 272, 489-498.

GLASER, J.S. (1978). Neuro-ophthalmology. Hagerstown, M.D., Harper and Row, p. 58.

GONZALEZ-SCARANO, F., HURTIG, H.I. (1981). Neurologic complications of coronary artery bypass grafting: case-control study. Neurology (Ny) 31, 1032-1035.

HODGE, A.J., DYMOCK, R.B., SUTHERLAND, H.D. (1976). A case of fatal fat embolism syndrome following cardiopulmonary bypass. J Thorac Cardiovasc Surg 72, 202-205.

KENDELL, R.E., MARSHALL, J. (1963). Role of hypotension in the genesis of transient focal cerebral ischemic attacks. Br Med J 2, 344-348.
KESSLER, J., PATTERSON, R.H. (1970). The production of microemboli by various blood oxygenators. Ann Thorac Surg 9, 221-228.

LEE, M.C., GEIGER, J., NICOLOFF, D., KLASSEN, A.C., RESCH, J.A. (1979). Cerebrovascular complications associated with coronary artery bypass procedures. Stroke 10, 107.

MEHIGAN, J.T., BUCH, W.S., PIPKIN, R.D., FOGARTY, T.J. (1977). A planned approach to coexistent cerebrovascular disease in coronary artery bypass candidates. Arch Surg 112, 1403-1409.

PRICE, D.L., HARRIS, J. (1970). Cholesterol emboli in cerebral arteries as a complication of retrograde aortic perfusion during cardiac surgery. Neurology (Minneap) 20, 12091214.

RUSSELL, R.W.R., BHARUCHA, N. (1978). The recognition and prevention of border zone cerebral ischemia during cardiac surgery. Q J Med 187, 303-323.

SHELDON, W.C., GRINFELD, L. (1971). Direct myocardial revasularization: venous autograft technique; postoperative assessment. Surg Clin North Am 51, 1043-1049.

STOCKARD, J.J., BICKFORD, R.G., SCHAUBLE, J.F. (1973). Pressuredependent cerebral ischemia during cardiopulmonary bypass. Neurology (Minneap) 23, 521-529.

STONEY, W.S., MULHERIN, J.L., ALFORD, W.C., BURRUS, G.R., FRIST, R.A., THOMAS, C.S. (1976). Unexpected death following aortocoronary bypass. Ann Thorac Surg 21, 528-531.

TORVIK, A., SKULLERUD, K. (1976). How often are brain infarcts caused by hypotensive episodes? Stroke 7, 255-257.

TUFO, J.M., OSTFELD, A.M. SHEKELLE, R. (1970). Central nervous system dysfunction following open-heart surgery. J Amer Med Assoc 212, 1333-1340.

TURNIPSEED, W.D., BERKOFF, H.A., BELZER, F.O. (1980). Postoperative stroke in cardiac and peripheral vascular disease. Ann Surg 192, 365-368. 